\title{
Understanding Student Experiences in a Near-Peer Resident Shadowing Program
}

\author{
Simon R. Turner, ${ }^{1,2}$ Jonathan White, ${ }^{1,2}$ Cheryl Poth, ${ }^{1}$ and W. Todd Rogers ${ }^{1}$ \\ ${ }^{1}$ The Center for Research in Applied Measurement and Evaluation, University of Alberta, Dvorkin Mailroom 2G2.07, \\ Walter MacKenzie Center, 8440-112 Street, Edmonton, AB, Canada T6G 2J2 \\ ${ }^{2}$ Department of Surgery, University of Alberta, Edmonton, AB, Canada T6G 2J2
}

Correspondence should be addressed to Simon R. Turner; sturner@ualberta.ca

Received 5 August 2013; Revised 3 May 2014; Accepted 7 May 2014; Published 18 May 2014

Academic Editor: Gary Velan

Copyright (C) 2014 Simon R. Turner et al. This is an open access article distributed under the Creative Commons Attribution License, which permits unrestricted use, distribution, and reproduction in any medium, provided the original work is properly cited.

Introduction. The preparation of medical students for clerkship has been criticized, both in terms of students' ability to understand their new role as clinical trainees and in their ability to carry out that role. To begin to address this gap, this paper reports the experiences of students in a shadowing program aimed at enhancing the preparedness of medical students for clinical training. The study examined a novel program, the Resident-Medical Student Shadowing Program, in which first-year medical students at the University of Alberta shadowed a first-year resident during clinical duties over the course of eight months. Methods. A study was conducted to assess the experiences of 83 first-year medical student participants who shadowed a first-year resident intermittently for one year. Student and resident participants' experiences were explored using semistructured interviews. Results. Students and residents experiences indicate that participation increased students' understanding of the clinical environment and their role within it and introduced them to skills and knowledge needed to perform that role. Students reported that a close relationship with their resident enhanced their learning experience. Conclusion. This study demonstrates that a low-cost program in which first-year students shadow residents may be a useful tool for helping prepare students for clerkship.

\section{Introduction}

In Canada, as in many areas of the world, medical education is divided into undergraduate and postgraduate phases. The undergraduate phase consists of medical school, typically four years in duration. This phase can be further broken down into preclerkship and clerkship, as students spend the majority of time in the beginning of medical school in nonclinical environments such as classrooms, laboratories, and small group interactions, while the latter half of medical school is usually devoted to clinical education in hospitals, clinics, and physicians offices. The postgraduate phase, known as residency, constitutes specialization training after graduation from medical school. The first year of residency is generally quite varied as residents are exposed to several specialties related to their chosen specialty of focus.

The transition in the undergraduate phase from preclerkship to clerkship can be difficult for many medical students [1]. Among the challenges faced are unfamiliar environments, new roles, and a lack of clinical knowledge and skills. The often abrupt transition to clerkship can be bewildering for students, who as Prince et al. found, may enter this phase "uncertain as to how to behave and act, mainly because they (do not) know what (is) expected of them" [2]. Radcliffe and Lester found that $50 \%$ of students studied did not feel well prepared for clerkship and 93\% thought a good introduction would make the transition easier [1]. Educators also found students unprepared to begin clinical duties, as 30-50\% of 192 American clerkship directors thought their students needed better training in the areas of history taking, physical examination, communication, professionalism, and care systems [3].

Early exposure to the clinical environment might help prepare students for clerkship, but such opportunities are often limited. Whereas there have been instructional programs focused on knowledge and skills [4], experiencebased approaches have been shown to decrease anxiety 
towards clerkship and increase role clarity [5]. However, these preparatory courses lacked measureable objectives, did not address all important transition issues and the vast majority (83\%) lasted only between one day and one week [6].

We developed a program to prepare students for clerkship and to address some of the issues encountered by previously studied preparatory programs. In this program, first-year students were paired using a computerized random number generator with a first-year resident. First-year residents were selected as the mentors because of their proximity to medical students in age and training level, their higher level of clinical expertise compared to medical students, and their varied schedule of clinical rotations. The students shadowed their residents during clinical activities once per month, for eight months, four to six hours at a time. Our program's development was informed by the findings that shadowing residents and senior medical students was of benefit for students [7], letting students "[learn] about the practice of medicine, the process of becoming a doctor, providers of healthcare, the nature of real patients and the procedures of medicine" [8]. The successes of such programs may be understood through the theories of situated learning and legitimate peripheral participation of Lave and Wenger, which describe how novices gain expertise through gradual and supervised increases in responsibility and involvement in a given occupation [9]. When that supervision is provided by fellow trainees at a level that is close, but still superior, to that of the program's learners, special benefits can accrue [10]. In a phenomenon known as near-peer teaching, enhanced social and cognitive congruence occurs between the learner and teacher, as has been described by Lockspeiser et al. [11]. These authors stress that exposure to near-peer role models can benefit students by providing insight into future experiences and confidence in adopting new roles. Indeed, Sarikaya et al. found that preclinical medical students were unsure about even the most basic aspects of the clinical experience, for example, not getting lost in the hospital, and participation in the RMSSP at its most basic level oriented students to these fundamental aspects of the environment [12]. Our program was developed with the intention of applying the benefits of near-peer interaction to first-year students, taking advantage of the knowledge, skills, and experience of first-year residents. The principle guiding our program was the hope that by being exposed to and participating in the role of the clinical trainee, students would gain a better understanding of the clinical environment and their role within it and gain the knowledge and skills needed to perform that role. As a program with no financial cost, needing little administrative work, this program is potentially highly sustainable and portable to other settings. The aim of this study was thus to better understand the effectiveness of this program in preparing first-year medical students for clerkship by examining the experiences of students in the program.

This paper describes part of the findings of our larger study of this resident shadowing program. Data related to other aspects of the program have already been published elsewhere. This includes a more detailed description of the program's development [13] and the findings of mixed methods randomized control trial that demonstrated that students gained increased understanding of and support for the professional behaviors described by the CanMEDS framework [14]. The findings presented here focus on the qualitative experiences of students in this program and have not been published before in full.

\section{Methods}

2.1. Study Design, Setting, and Participants. To better understand the experiences of students in this program, we conducted a qualitative study embedded within a larger randomized control trial. 173 of 183 first-year students and 83 of 167 first-year residents from the University of Alberta volunteered to participate. Residents volunteered from over twenty clinical specialties, including medical and surgical specialties. Of the students, 83 were randomly selected by computerized coin toss to participate in the program and were paired, again at random, with a first-year resident. Because of the limited number of resident volunteers we were unable to pair the remaining 90 interested students with a resident. Findings from the larger randomized control trial have been published elsewhere $[13,14]$. This study focuses on the qualitative experiences of students and residents who participated in the shadowing program.

2.2. Data Analysis. Qualitative data were collected using semistructured small group interviews with the purpose of exploring participant experiences. Twenty-seven volunteer student participants and three volunteer resident participants were interviewed, utilizing a thematic analysis approach to analyze interview data [15]. Two authors (Simon R. Turner and Jonathan White) first analyzed the data independently. One author used a deductive approach, looking for how data addressed the research questions and whether any unexpected data did not fall within a research question. Next, for each theme, all of the relevant meaning units from each interview were grouped and reviewed together. Key ideas were noted and key excerpts were selected that supported each key idea. The list of key ideas and their supporting excerpts were then reexamined and used to create a description for each theme. A summary of each theme was created and within each theme exemplar quotations were selected that represented the responses related to that theme. A second author used an inductive approach to identify themes in a similar fashion but without reference to the research questions. Finally, the two raters came together to derive a single conceptual framework that fully encompassed the themes identified by each rater within a single structure.

Approval was granted by the Health Research Ethics Board of the University of Alberta.

\section{Results}

Responses from the interviews of students and residents provided insight into what it was like for students to participate in the program, and the themes generated from their descriptions included depictions of both formal and informal learning of students which contributed to their 
preparation to be a clinical medical student. Each of the positive aspects of the learning experience was enhanced by the close relationship that developed between the student and resident.

3.1. Formal Learning. By observing their resident, or by participating in clinical duties themselves, students reported that they learned a great deal of declarative medical knowledge, as well as skills and nondeclarative knowledge such as history taking, physical examination, and communication skills. Students emphasized the importance of being able to apply what they had learned elsewhere to a practical setting and stated that, for example, while they had received introductory instruction on performing histories and physical exams, this was their first opportunity to apply the skills in a real world setting and see the connection to actual disease processes.

Students described being taught a great deal of declarative medical knowledge by their residents and found that seeing diseases and treatments in real life made them easier to understand. The students were able to use what they had learned in class with the patients they saw while shadowing. Several students made comments such as "I got to apply a lot of the stuff we learned in lecture... and I actually could connect things." They found that seeing diseases and treatments in real life made them easier to understand.

Among the skills and nondeclarative knowledge students reported learning from their residents, improved communication skills were emphasized. Students stated that they learned a great deal from practicing communication themselves and also by observing their resident and other physicians, as one student remarked: "Every time you get to see a different doctor talk to patients it's like an extra little skill in your arsenal."

3.2. Informal Learning. In addition to the medical skills and knowledge that residents explicitly taught their students, students also learned a great deal about the implicit or hidden nature of the clinical environment through observation. Students repeatedly described learning "things they do not teach you in class." The most commonly raised aspect of this informal learning related to the social structure of the healthcare setting. This included how a hospital worked and how to interact in a hospital setting based on the basic behavior and etiquette of the clinical environment and how these considerations are determined by a social hierarchy. Respectful interaction with senior members of the hierarchy was stressed as important, and several students reported being glad to learn about this social structure before they were immersed in it. One student was thankful to have learned "things that you would not know... the hierarchy of how the hospital works" stating "Its [sic] kind of better to learn it before you make a fool of yourself, or before you make an enemy of somebody."

3.3. Preparation to Be a Clinical Student. Students reported that their experience had given them both a better ability to perform the job of a clinical trainee and an appreciation for role of a clerkship student and the life and lifestyle that go with it. Consequently, they felt better prepared for the eventual transition to clinical duties. Students reported that the experience gained in the program "might separate (them) in third-year" from colleagues who had not been in the program. Part of that feeling of preparedness was attributed to the practical skills and knowledge that they learned in the program and that would be useful to them as clinical trainees. Residents agreed that the program had made students better prepared for third year. As one stated, "I felt my med student became more comfortable just being around and talking with patients."

Students also reported gaining an understanding about the nature of clerkship as they discussed the life and lifestyle of clinical training during their shadowing sessions. One of the fundamental experiences that students reported was entering the role of the clinical trainee, "being in a hospital, experiencing patient care from a physician's perspective." Through experiencing that role and through discussions with their residents, students' understanding of that role increased in the program. Furthermore, being able to observe what their life might be like during clerkship was reported by students as important for gaining an idea of the stresses and pressures that come with that phase of education. Students stated that they had contemplated what their life would be like once they began their clinical training and in particular what their experience of working as a clinical trainee would be like. They noted that before participation in the program they had little way of anticipating what that experience would be but through the program they had gained an idea of what to expect. One student suggested "it's not going to make it any better when it's happening (to you), but...you're still better prepared." Being able to experience the life of a clinical student firsthand removed some doubt and anxiety about that phase of their career.

3.4. The Student-Resident Relationship. Both students and residents reported that the relationship formed between them was one of the most important aspects of the program and one that served to greatly enhance the educational potential of the program. Students described viewing their residents as a "mentor," "friend," or "big sister" and they found the residents to be easy to relate to on both a personal and professional level, especially in contrast to staff physicians. The proximity of the residents to the students in terms of age and educational level seemed to foster a mutual understanding. As one student said, in a typical statement:

"(Residents are) closer to you in age, they're closer to you in training...so they know what its like to be learning all of this stuff brand new."

There was a clear impression shared by the students that because the residents were only three years ahead in their training, they had greater empathy and understanding for what the students were experiencing. As one student commented, "They are fresh out of med school, they remember what its [sic] like to be where we are. It's nice to build that relationship and have that trust." 
Students were able to strengthen their rapport with their resident due to repeated interactions over time. Students described having appreciation for "having somebody that you get to know throughout the year that you can always go to for shadowing." They described feeling less "pressure" to perform or to always "know the right answer," which allowed students to have more frank and honest discussions with their residents. Residents were also described as highly dedicated and highly available as teachers and were again positively compared against staff physicians in this regard.

\section{Discussion}

This study demonstrates that a program in which firstyear medical students shadow first-year residents can help students feel prepared for the experience of clinical training. This allowed them to develop an understanding of the nature of the clinical environment by introducing them to the role of the clinical trainee and by teaching them knowledge and skills needed to perform that role.

Ten Cate and Durning, in their discussion of nearpeer teaching, suggested that "a trusting relationship with a peer who holds no position of authority might facilitate self-disclosure of ignorance and cognitive errors, enabling subsequent diagnosis and correction" [10]. By providing repeated interaction with a mentor close to the students in age and training, rather than a staff physician who might not have related as well to the students, this program created the potential for students to develop a strong relationship with their resident, enhancing the learning students experienced. Furthermore, the proximity of the residents to the age and training level of their students gave the residents greater understanding of the students' needs, which "allows the... teachers to use language that their learners understand and to explain concepts at an appropriate level" [11].

Participation in this program provided students with experiences that foreshadowed future responsibilities, thereby providing a better understanding of their future role in the clinical training environment. Exposure to near-peer role models can benefit students by allowing insight into future experiences and confidence in adopting new roles [10].

Students were able to experience the clinical environment firsthand with the guidance of a near-peer close to them in training. These findings related to the apprenticeship learning theory of Lave and Wenger who stated that as novices enter a vocation and gradually participate in more complex tasks they learn both about the "community of practice" and about how to perform that vocation [9]. As such, students also learned about a new role that they would later be expected to adopt in the environment of the clinical clerkship. Students were able to experience the role of the clinical trainee and observe firsthand the duties of a medical student in clerkship, so that when they arrive in the clinical environment they would know what is expected of them. In contrast to other preparatory programs that have tended to be one week in duration or less [6], this program took place over the course of eight months, offering a much greater volume and duration of clinical exposure. This increased amount of experience may have further contributed to the students' understanding of their role in the clinical environment and represents a distinct advantage of this program.

This program also provided students with knowledge and skills relating to the clinical environment, for example, performing histories and physical examinations and communicating with patients and other health professionals; learning that is enhanced by occurring in a practical context with real patients. Furthermore, because the residents were themselves clinical trainees, observing and participating in the resident's duties taught students skills and knowledge that were necessarily relevant to the role of the clinical trainee and more immediately relevant than the more extensive skills and knowledge demonstrable by a staff physician. By learning to perform these aspects of the clinical trainee's duties, students increased their competence to fulfill that role, including four areas in which students are often underprepared, namely, history taking, physical examination, communication, and professionalism [3]. As such, this program not only informed students about the nature of clinical training and the role of the clinical trainee, but also introduced them to some of the tools needed to succeed in that environment and in that role.

Students' preparation to participate in the clinical environment was also increased by an introduction to more complex aspects of the environment, such as the roles of staff physicians, residents, and other healthcare professionals. By interacting with residents, staff physicians, and other health professionals and by seeing how they interact with each other, students in this program were afforded a unique, early opportunity to learn about this environment and to begin the socialization process. Judging by the remarks of one student who feared making "an enemy" through ignorance of the medical societies unwritten code of behavior, this aspect of the learning that occurred in this program is an important one to students. As a result of gaining insight into the hidden curriculum of medical culture, students may be better prepared to engage in the social aspect of the clinical environment and to succeed not just socially but in other domains as well. Of course, the knowledge base of residents used as teachers is never complete, and the skills and information passed on to students may be imperfect compared to what they would learn from a staff physician. Residents' views on the hidden curriculum may likewise be different from those of other members of the healthcare team. This may either be viewed as a limitation of using residents as teachers, or as a positive way to provide unique and varying viewpoints on both the medical and nonmedical aspects of the clinical setting.

All of these benefits for students were accomplished with no financial cost and minimal administrative effort, indicating the potential for a highly sustainable program. However, it will be important to continue to observe the impact of the program throughout the students' introduction to clinical training in medical school and residency to assess whether past participation in this program continues to provide a benefit. 
The conclusions available from this study are limited by the study's intent and design. This study describes the experiences of students within a resident shadowing program. While those experiences may suggest that a positive impact on student preparedness for clerkship may have occurred, such a conclusion would be outside the mandate of this study. For an investigation into the effect of participation on students' actual preparedness for clerkship, as well as techniques and challenges of establishing such a program, readers are referred to our previously published work $[13,14$, 16].

This study was limited by the interview participation rate, especially among residents, of whom only three were available to be interviewed, partly due to scheduling difficulties. For this reason, data from the resident interviews was limited largely to corroborating findings from student interviews. Future studies with repeated iterations of the program will attempt to replicate our findings and will examine the effects on students as they enter the clinical training environment. Studies examining alternate formats of the program including a comparison of the benefits for first- and second-year students and the impact of a resident teacher-training course on the effectiveness of the program would also be of significant value.

\section{Conclusion}

This study revealed the ways in which students' experiences in a resident shadowing program, learning declarative knowledge, non-declarative knowledge and clinical skills, and being introduced to the experience of clinical training and medical culture and social structure, can affect students' feeling of preparation for learning in the clinical environment. It is our hope that by better understanding the experiences of students in such a program, we may be better able to continue to develop similar efforts that can ease the transition from preclerkship to clerkship, and possibly contribute to the success of students in the clinical environment.

\section{Conflict of Interests}

The authors have no conflict of interests to declare.

\section{Acknowledgments}

All contributors are listed as authors. There are no financial disclosures or acknowledgements to declare.

\section{References}

[1] C. Radcliffe and H. Lester, "Perceived stress during undergraduate medical training: a qualitative study," Medical Education, vol. 37, no. 1, pp. 32-38, 2003.

[2] K. J. A. H. Prince, H. P. A. Boshuizen, C. P. M. van der Vleuten, and A. J. J. A. Scherpbier, 'Students' opinions about their preparation for clinical practice," Medical Education, vol. 39, no. 7, pp. 704-712, 2005.

[3] D. M. Windish, P. M. Paulman, A. H. Goroll, and E. B. Bass, "Do clerkship directors think medical students are prepared for the clerkship years?” Academic Medicine, vol. 79, no. 1, pp. 56-61, 2004.

[4] H. Chumley, C. Olney, R. Usatine, and A. Dobbie, "A short transitional course can help medical students prepare for clinical learning," Family Medicine, vol. 37, no. 7, pp. 496-501, 2005.

[5] E. H. Chittenden, D. Henry, V. Saxena, H. Loeser, and P. S. O'Sullivan, "Transitional clerkship: an experiential course based on workplace learning theory," Academic Medicine, vol. 84, no. 7, pp. 872-876, 2009.

[6] A. Poncelet and B. O'Brien, "Preparing medical students for clerkships: a descriptive analysis of transition courses," Academic Medicine, vol. 83, no. 5, pp. 444-451, 2008.

[7] A. Jones, S. C. Willis, P. J. McArdle, and P. A. O’Neill, “Learning the house officer role: reflections on the value of shadowing a PRHO," Medical Teacher, vol. 28, no. 3, pp. 291-293, 2006.

[8] C. L. Alford and D. M. Currie, "Introducing first-year medical students to clinical practice by having them "shadow" third-year clerks," Teaching and Learning in Medicine, vol. 16, no. 3, pp. 260-263, 2004.

[9] J. Lave and E. Wenger, Situated Learning: Legitimate Peripheral Participation, Cambridge University Press, Cambridge, UK, 1991.

[10] O. T. ten Cate and S. Durning, "Dimensions and psychology of peer teaching in medical education," Medical Teacher, vol. 29, no. 6, pp. 546-552, 2007.

[11] T. M. Lockspeiser, P. O'Sullivan, A. Teherani, and J. Muller, "Understanding the experience of being taught by peers: the value of social and cognitive congruence," Advances in Health Sciences Education, vol. 13, no. 3, pp. 361-372, 2008.

[12] O. Sarikaya, M. Civaner, and S. Kalaca, "The anxieties of medical students related to clinical training," International Journal of Clinical Practice, vol. 60, no. 11, pp. 1414-1418, 2006.

[13] S. R. Turner, J. White, C. Poth, and W. T. Rogers, "Preparing students for clerkship: a resident shadowing program," Academic Medicine, vol. 87, pp. 1288-1291, 2012.

[14] S. R. Turner, J. White, C. Poth, and W. T. Rogers, "Learning the CanMEDS roles in a near-peer shadowing program: a mixed methods randomized control trial," Medical Teacher, vol. 34, pp. 882-892, 2102 .

[15] J. W. Creswell, Research Design: Qualitative, Quantitative, and Mixed Methods Approaches, Sage Publications, Thousand Oaks, Calif, USA, 2009.

[16] S. R. Turner, J. White, and C. Poth, "12 tips for developing a near-peer shadowing program to prepare students for clinical training," Medical Teacher, vol. 34, pp. 792-795, 2012. 

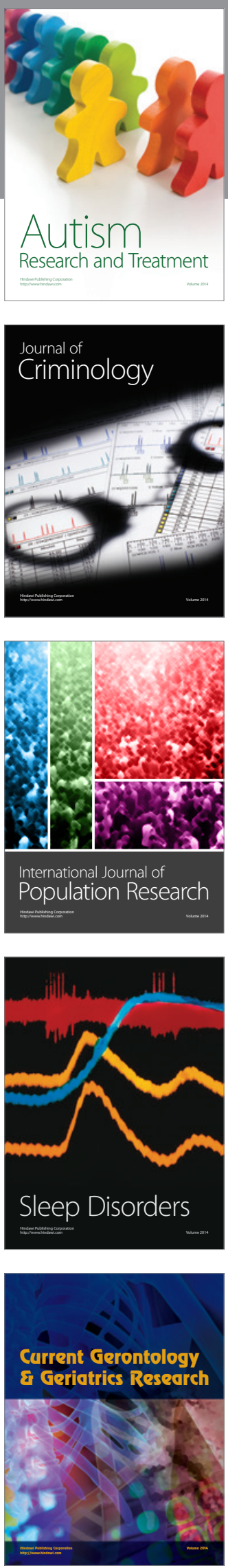
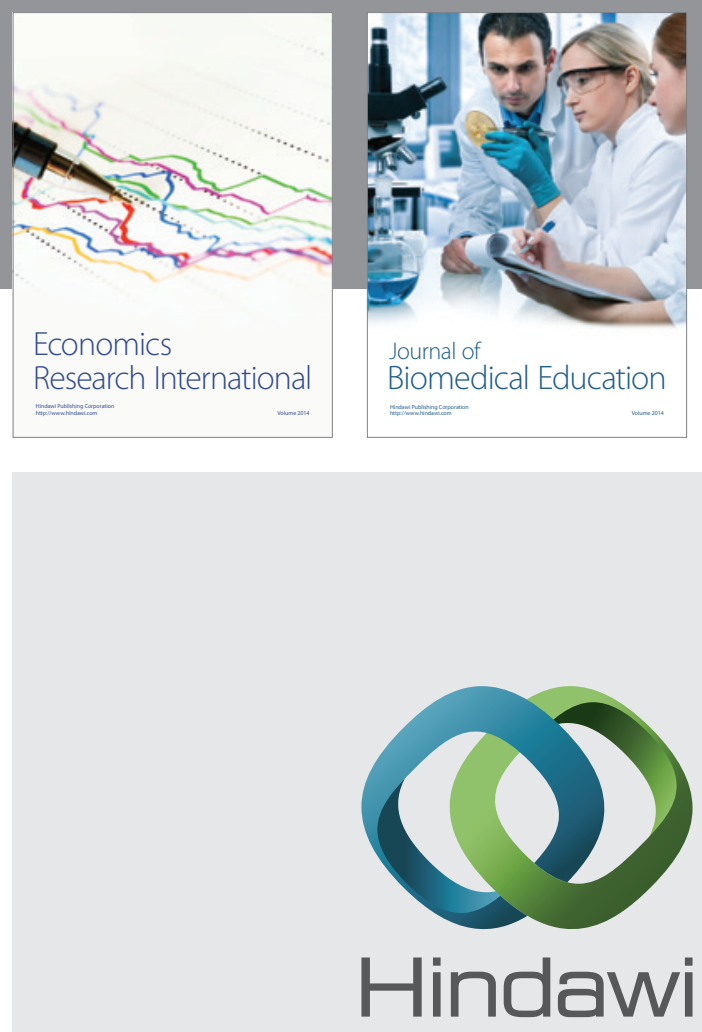

Submit your manuscripts at

http://www.hindawi.com
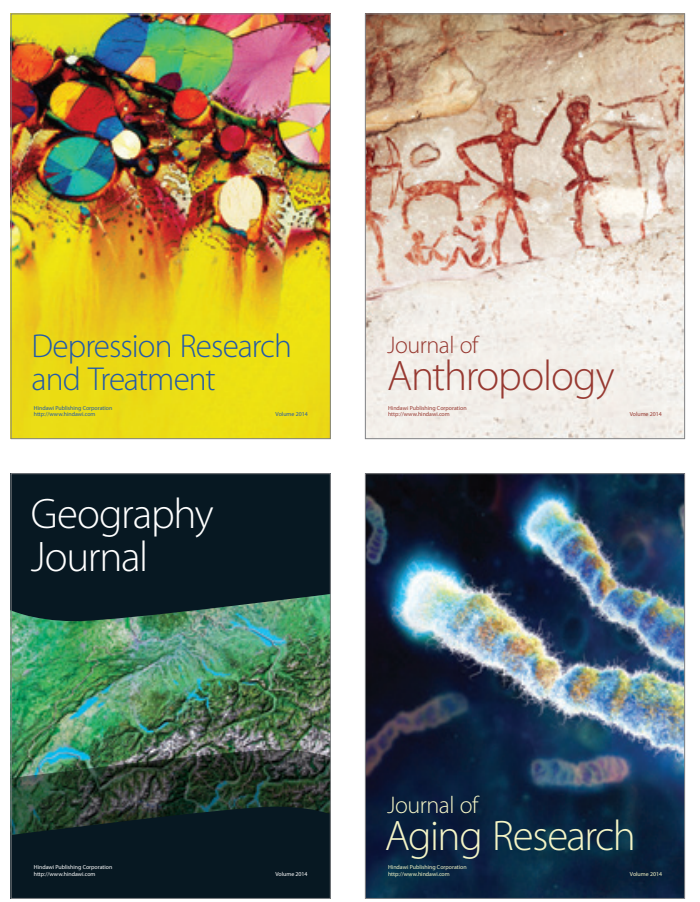
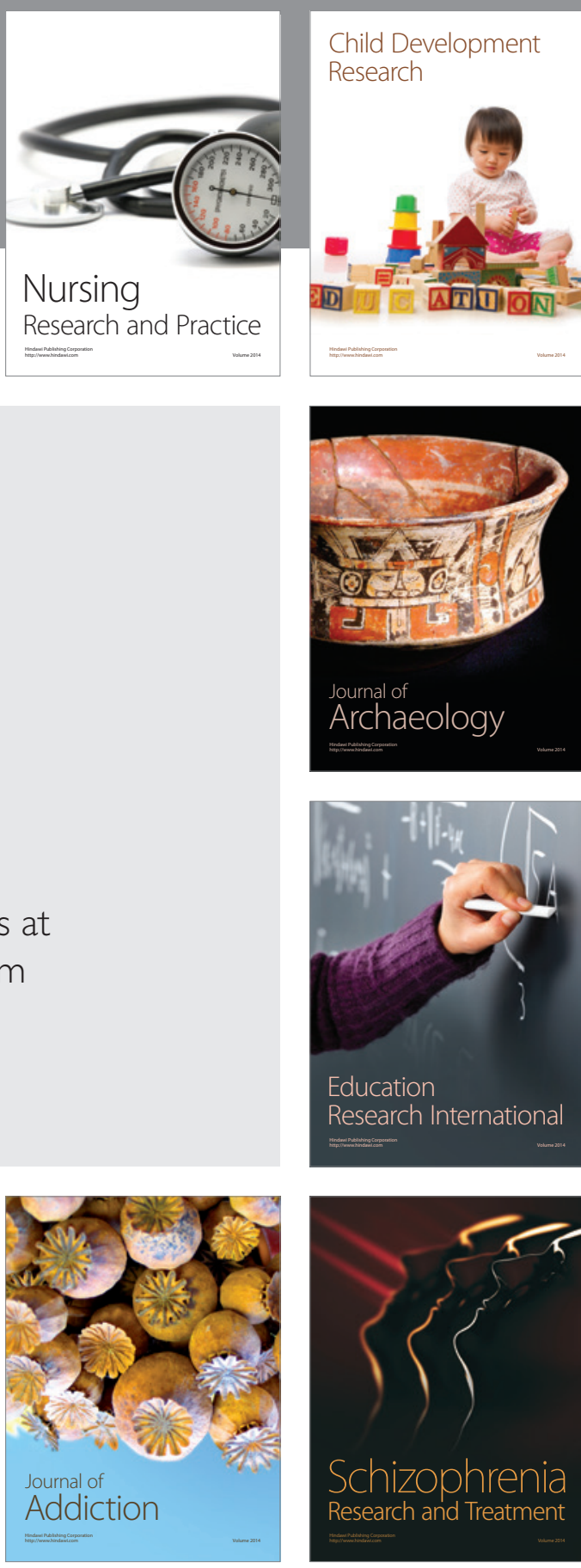

(D)
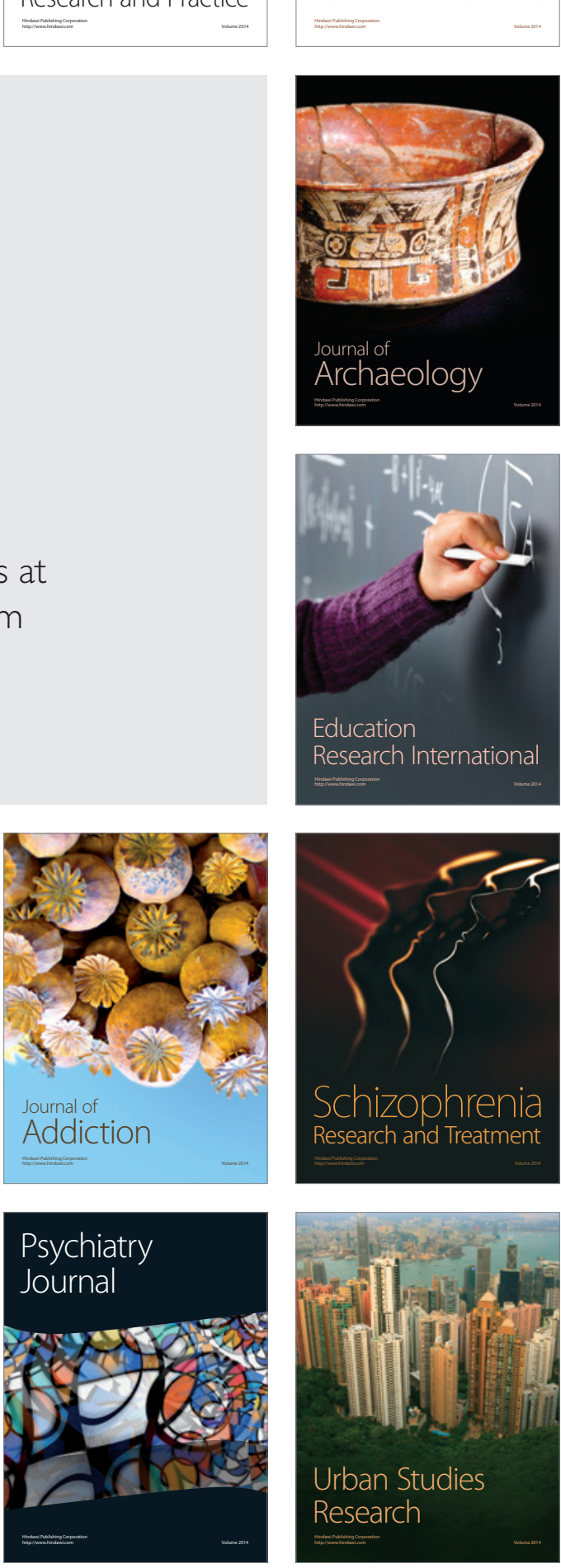